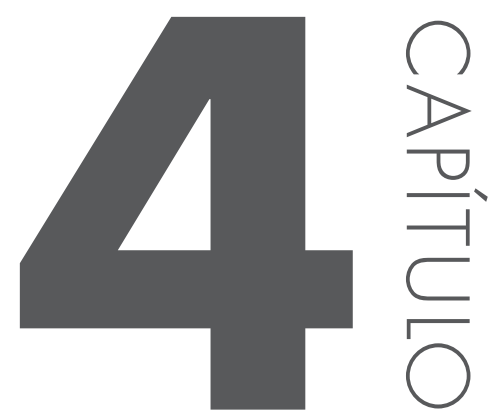

\title{
GEOGRAFIA, ÉTICA E SAÚdE PÚBLICA NO CONTEXTO DA DEPENDÊNCIA Química
}

Santana, Maria Aparecida Guimarães Santana 1 *; Stacciarini, José Henrique Rodrigues 2

1 Mestranda do Programa de Pós-Graduação em Geografia-RC/UFG

2 Professor do Programa de Pós-Graduação em Geografia-RC/UFG

* email: cidacaic2012@hotmail.com 
Resumo: Este texto busca refletir como as ciências podem atuar em conjunto, contribuindo para o tratamento da dependência química de forma responsável e ética, atuando sobre seus diversos aspectos citando o reducionismo, onde os caminhos a seguir para conseguir vencer o crack passam por diversas ideias e múltiplas teorias, onde a Geografia contribui de forma significativa ao ajudar a analisar o espaço vivido e diagnosticar os diversos fatores que se interagem, contribuindo ou não para o consumo de crack.

\section{Palavras-chave: Dependência química. Tratamento. Crack. Lugar.}




\section{Introdução}

Partindo-se da concepção de que a dependência química de crack em alta escala, como atualmente tem ocorrido em todo Brasil, tem relação com as mudanças ocorridas na sociedade humana, sejam estas de ordem econômica, politica ou sociocultural. Tais fatos alertam para a necessidade da construção de novos paradigmas que se sustentem na multidisciplinariedade, aglomerando diversas análises, múltiplas teses e inúmeras teorias, a fim de transpor barreiras históricas, erguidas em torno de um conhecimento fragmentado e exclusivo de cada área do conhecimento.

A Geografia há muito tem pensando as questões ligadas à saúde, e aos poucos foi ampliando a escala de análise, incorporando também a dimensão social das 
doenças. Deste modo, a pretensão aqui é incluir nesta reflexão o viés sociedade/saúde/drogas, em um debate efervescente, que, ao gerar polêmicas, resulte em respostas para construção de alternativas para um mundo cheio de novos desafios, entre eles o tratamento da dependência química de crack.

Cabe aqui ressaltar que, a Geografia, mesmo aquela que ultrapasse o paradigma ambientalista-naturalista, que tenha fundo social, que incorpore novas categorias de análise, as quais permitam entender o nexo casual entre o consumo de cracke o espaço capitalista vivido, não pode como disciplina única entender a dependência química e seu tratamento, isto devido a complexidade do tema que se desdobra em várias vertentes interligadas.

Assim, diante do desafio de tratar, de forma ampla e eficaz, o dependente químico de crack, não é possível estabelecer verdades absolutas em relação ao objeto e à área de estudo de cada ciência, mais sim, evitar o reducionismo em busca de um conhecimento onde as diversas áreas deste contribuem e se completam num debate com o seu "saber", para atuar sobre a problemática da dependência química de crack em suas múltiplas facetas.

Deste modo, o presente trabalho apoia-se em uma pesquisa interdisciplinar e busca refletir sobre o tratamento da dependência de crack e como o espaço de vida com suas experiências concretas podem interferir de foram positiva ou não nas relações tecidas entre o individuo e seu espaço, bem como a construção de seus hábitos inclusive o consumo de drogas.

\section{Desenvolvimento}

A Geografia acredita colaborar para o entendimento de quais e como os fatores do ambiente podem contribuir ou prejudicar no tratamento da dependência química. Sendo assim, busca-se entender a Geografia da Saúde para além das doenças infecto-parasitárias, de forma a compreender o espaço vivido e o consumo de crack, onde os diversos fatores interagem, atuando de forma positiva ou negativa sobre os indivíduos.

Desta maneira, a Geografia faz um diálogo com a medicina e a biologia, sendo possível a discussão sobre o tratamento da dependência química através de um encontro de saberes que possa entender as relações do homem com o ambiente de forma integral em toda sua complexidade, de forma que as interações entre o social, econômico, psicológico, cultural, físico e biológico passem a ser percebidas e analisadas. Stacciarini (2002) acrescenta que, 
Porém é bom que se diga, isto não quer dizer que o paradigma socioespacial, fortemente estabelecido sobre a relação sociedade/natureza deixa de ter valor. No fundo o que se procura é acrescentar outras "categorias geográficas" tais como ética, desejo, solidariedade, subjetividade, comunidade, cotidiano, lugar, indivíduo, emoção, etc, as quais tornam-se importantes nas pesquisas geográficas nos últimos 12 anos (STACCIARINI, 2002, p. 49).

Para Barbosa (2013), existe uma constante reformulação na Geografia da Saúde, o que permite a ampliação do leque de análises. E nossas questões são incluídas no debate da saúde urbana nas sociedades modernas. Assim, novos conceitos, teorias e metodologias são reformulados de forma a investigar com o espaço que contém como o ambiente se relaciona com a saúde.

Castro em sua obra "Geografia da Fome" traz para a Geografia um debate importante, pois, ao discutir o subdesenvolvimento, a pobreza e a miséria, o faz com relação a estes elementos e às condições físicas e mentais da população, não como produto simples de causas ou fatores naturais, mas sim, como problema, sobretudo, político. Sendo assim, observando sobre a miséria humana, Castro (1953), aponta que,
A fome age não apenas sobre os corpos das vítimas da seca, consumindo sua carne, corroendo seus órgãos e abrindo feridas em sua pele, mas também age sobre seu espírito, sobre sua estrutura mental, sobre sua conduta moral. Nenhuma calamidade pode desagregar a personalidade humana tão profundamente e num sentido tão nocivo quanto a fome, quando atinge os limites da verdadeira inanição, excitados pela imperiosa necessidade de se alimentar, os instintos primários são despertados e o homem, como qualquer outro animal faminto, demonstra uma conduta mental que pode parecer das mais desconcertantes (CASTRO, 1953, p. 51).

Observa-se que, se substituir algumas palavras no texto acima e ler crack onde está escrito fome e trocar vítimas por dependência química, torna-se o texto representativo de um fenômeno atual, que desafia as ideias e as categorias do pensamento científico em busca de soluções para seu enfrentamento. Nestes termos acreditase que o consumo de crack e mesmo seu tratamento não pode ser tomado à parte, alheio a ordem vigente, apenas como uma questão de saúde, que deve ser avaliada e tratada apenas por profissionais de saúde, mesmo porque, sabe-se que a dependência química é resultante da interação de vários fatores, inclusive das patologias sociais.

Santos (1996), diz que, no espaço, as formas são dotadas de conteúdos que ganham significados pela ação humana, sendo, portanto, também frutos do cotidiano, 
na visão de Barrios (1986). Esta categoria é uma unidade de práticas espaciais, onde a base material ou física é modificada pela ação humana em interação com os planos econômico, cultural e político. Lefevre (1991) acrescenta que o espaço é produção da sociedade, das relações sociais de produção, além disso, traz o conceito de espaço percebido como aquele da experiência corpórea do social, numa relação dialética com o espaço.

Moreira (1982) entende o espaço geográfico como uma rede de relações determinadas pelo social ou "totalidade estruturada de formas espaciais". Outra referência importante é Tuan (1980) que coloca no conceito de espaço um viés comportamental onde a percepção aparece como fundamental. Deste modo, as diversas formas de ver e refletir sobre o espaço se completam a fim de tratar da temática da drogadição em toda sua complexidade. Em outras palavras, abordagens cultural-simbólicas, comportamento-percepção e econômicas sociais não se excluem, mas sim, permitem uma visão mais ampla e humana do lugar e das situações onde se vive.

Por sua vez, Gomes (1996) argumenta que o espaço vivido é tomado como dimensão da experiência humana nos lugares que dão importância às redes de valores e de significados. Assim, buscam-se também, no espaço vivido, elementos que possam interferir no processo de drogadição e na recuperação do dependente de forma a atuar sobre todas as variáveis que interferem de forma negativa ou positiva no processo. Entretanto, o reducionismo pode tornar o serviço oferecido no tratamento

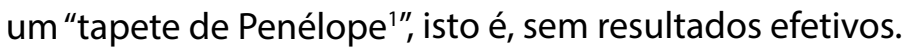

Para muitos, refletir e mapear as vulnerabilidades e potencialidades do lugar onde se vive, pode ser uma ferramenta de planejamento de ações preventivas e terapêuticas na comunidade local. Portanto, situações como pobreza extrema, desorganização comunitária, assistência de serviços básicos precários ou ausentes, violências e falta de vínculo cultural ético e religioso pode se ligar ao individual como predisposição genética, curiosidade, transtornos mentais, famílias desestruturadas, onde ter-se uma combinação potencializadora para o uso e para a manutenção do vício.

Desta forma, o ambiente e suas interações podem de acordo com sua estrutura local atuar como força mantenedora da dependência química de crack, sendo que o tratamento médico rompe o elo fisiológico, mas é necessário romper o elo socio-

'Penélope foi uma heroína mítica, casada com Ulisses, que pouco depois do casamentou partiu para a Guerra de Tróia, ficando ausente por um longo período. Nesta fase Penélope foi importunada por inúmeros pretendentes, mas acreditando na volta de Ulisses, lançou mão de um artifício para ganhar tempo. Alegou que teceria um tapete, comprometendo-se em fazer a escolha do pretendente quando a obra estivesse pronta. Durante o dia, aos olhos de todos Penélope tecia, a noite, secretamente, desfazia o trabalho feito. Desta forma "Tapete de Penélope" passou a ser uma expressão proverbial, para designar qualquer coisa que está sempre sendo feita, mas nunca é terminada. 
cultural-econômico que une a substância a valores, símbolos, vestimenta, dinheiro, poder e relacionamento que se materializam no espaço, criando um modo de vida peculiar. Neste contexto, é necessário estruturar este ambiente de forma material e imaterial para se desenvolver novas habilidades e competências no usuário e seus familiares, Siena e Mesquita (2006), numa escala macro, acrescentam que,

\begin{abstract}
Os encontros nos espaços públicos revelam o grau de civilidade da população e podem conter pressupostos da ordem democrática. Aliás, o direito à cidade é o direito de habitar, circular, receber, educar, e ter saúde, etc. Deste modo, vulneráveis são todos os que têm ameaçadas as condições de suas competências fundamentais para o exercício da cidadania, depende basicamente das condições de vida que as cidades oferecem às crianças e adolescentes (SIENA; MESQUITA, 2006, p. 32).
\end{abstract}

Assim, o tratamento da dependência química deve ser considerado como um conjunto de técnicas e intervenções desenvolvidas com o intuito de favorecer a abstinência, bem como melhorar a qualidade de vida do funcionamento social do usuário. Dessa forma, o tratamento deve possuir metas específicas, mensuráveis e estabelecidas com o paciente. Ribeiro e Laranjeira (2010) destacam ainda que os usuários de crack são os que menos buscam ajuda entre os que utilizam drogas ilícitas, postergando ao máximo a busca por tratamento e restringindo-os às situações agudas, em que se usa abordagens em ambiente de internação.

Os mesmos autores argumentam que o crack atua sobre o sistema de recompensa (núcleo do prazer no cérebro), cuja função primordial é promover e estimular comportamentos que favoreçam a manutenção da vida e da espécie, produzindo efeitos agradáveis e corrompendo os mecanismos fisiológicos, visando a produção de prazer químico em detrimento de aprendizados fundamentais para o amadurecimento pessoal dentro do contexto social.

Esch e Stefano (2004) corroboram com essa discussão ao elucidarem que,

Cada indivíduo tem motivações pessoais para alcançar aquilo que possibilita sua sobrevivência, e de sua espécie. Tal motivação é medida por circuitos neuronais como o sistema de recompensa. Ao atingir seus objetivos, o indivíduo se sente bem (prazer, recompensa). Além disso, as estratégias e planejamentos que utilizou para alcançá-los amadurecem-no e passam a fazer parte de seu patrimônio neurobiológico, o estímulo motivacional normal é perdido, uma vez que o mesmo resultado pode ser obtido pelo uso de substância psicoativas, capazes de agir sobre o circuitos neuronais de modo muito mais intenso. Esse novo circuito corrompe o anterior e vai se consolidando operacionalmente no sistema nervoso central (SNC) - quanto mais perdurar, menos reversível será (ESCH; STEFANO, 2004, p. 46). 
A partir das questões abordadas, percebe-se que o usuário de crack apresenta grande vulnerabilidade em apresentar co-morbidades psiquiátricas como, transtornos de humor ou quadro psicóticos, o que dificulta ainda mais a busca por ajuda. Outro fator a ser considerado está relacionado ao grande mal-estar, causado pela falta de droga, chamado de "fissura" que parece ser uma das grandes dificuldades para o usuário aderir ao tratamento. Donato et. al. (2010) ressaltam o assunto e evidenciam que,

O desejo intenso de consumir e a lembrança dos efeitos desejados da substância em meio ao desconforto de falta da droga é denominado "fissura" ou "craving". Estes sintomas são decorrentes do bloqueio prolongado da receptação da dopamina, causado pelo uso crônico, acarretando a diminuição dos níveis de dopamina, tendo como consequência uma sensibilização de receptores dopaminérgicos e hipofunção dopaminérgica, levando a comportamento de fissura e busca constante da droga. Nos usuários de crack esta "fissura" é mais elevada, fazendo com que os sintomas sejam mais proeminentes e a busca da droga mais frequente (DONATO et. al., 2010, p. 78).

Nesse contexto, Ribeiro (2010) pondera que, em função do aumento do consumo de crack e seus fortes efeitos no cérebro do paciente é necessário criar enfermarias especializadas, as quais devem ser empregadas nos diferentes ambientes hospitalares, pois, na maioria das vezes, muitos não estão preparados para cuidar da intoxicação e da síndrome de abstinência de crack. Sabe-se da existência de alguns quadros graves, cujos protocolos ainda não estão disponíveis, mas que contribuem para o abandono e confirmam a necessidade de mudança urgente do modo existencial para o tratamento da dependência no Brasil.

Desse modo, a internação em ambientes especializados, na primeira etapa do tratamento é um procedimento recomendado por muitos especialistas em saúde mental, a fim de que ocorra a desintoxicação através de um tratamento estruturado, visando o alcance da manutenção da abstinência. A dependência química, como qualquer outra doença, pode ser gerenciada, mas é necessário um processo de readaptação para que a pessoa possa viver sem drogas. Assim, após um período variável, de acordo com a gravidade do caso, o dependente pode ser encaminhado para a internação parcial ou ambulatório, conforme suas necessidades.

Emergem, por esta via, também a questão ética do tratamento e da pesquisa no caso da dependência química infelizmente ainda existem diversos "charlatões" oferecendo a cura do problema de forma rápida, estes locais de "tratamento" utilizam choques elétricos, trabalho forçado, tortura física e psicológica, onde os leigos tratam uma doença crônica seria, que por se tratar de assunto de saúde pública, a dependência química do crack necessita de profissionais qualificados, como médicos, 
psicólogos, psiquiatras tendo como base programas definidos. Mas devido a falta de fiscalização de órgãos públicos competentes, o segmento da dependência química tornou-se terreno fértil para aqueles que se aproveita do desespero de famílias de usuários de crack em busca de internação, tornando-se assim um negocio altamente lucrativo.

Destaca-se que uma abordagem sobre a problemática do crack deve levar em consideração o fato de os usuários formarem grupos heterogêneos, além disso, suas particularidades social, econômica e cultural devem ser consideradas para embasar intervenções de saúde e sociais necessárias ao tratamento. Velho (1979) e Bucher (1992) enfatizam o papel desempenhado pela estigmatização das drogas ilícitas e de seus usuários na sociedade brasileira, com suas desigualdades na falta de um debate público e com a repetição de ideias falseadas, autoritárias e preconceituosas, operando uma desqualificação e demonização do usuário, o que leva a uma cristalização homogeneizante da sua cultura, acarretando em sua maior marginalização. $\mathrm{O}$ reducionismo dessa estereotipia serve também para encobrir alguns dos reais problemas estruturais da sociedade.

Portanto ao se refletir sobre a dependência química de crack é necessário levar em consideração as relações de multicausalidade que compõem o quadro da doença, o que impõe as ciências envolvidas no processo, inclusive a geografia da saúde uma responsabilidade ética para a produção de conhecimentos de forma dialética que possa abrigar diversas interpretações de forma integradora num contexto onde o espaço passe a ser visto como elemento ativo que interage com outros elementos do ambiente afetando as relações integrais do ambiente de vida.

\section{Considerações Finais}

Diante de todas as adversidades enfrentadas pelos dependentes químicos de crack e seus familiares na busca pelo tratamento sejam relativas ao preconceito social ou pela falta de políticas públicas direcionadas aos usuários que estão em recuperação integral, busca-se refletir sobre a necessidade de ações emergenciais e preventivas que implantadas de forma ética e pautadas na coerência e nos conhecimentos científicos produzidos em conjunto pelas diversas áreas possa atuar de forma efetiva nos múltiplos aspectos da dependência química.

Observa-se neste estudo a importância do lugar, ou seja, do contexto de onde se vive seus aspectos materiais e imateriais que criam fatores de risco ou proteção onde o risco para o uso de crack e mesmo para a manutenção do vicio. Espaços aonde a situação social, econômica e da disponibilidade de recursos de saúde e assistência aos direitos básicos mostram-se de forma diferenciada, criando situações complexas 
que demandam políticas públicas especificas.

Neste sentido para entender a amplitude dos problemas causados pelo uso de crack percebe-se a necessidade de alargar a busca teórica num dialogo com várias áreas do conhecimento através de um conjunto plural de fontes bibliográficas que possam apontar caminhos que permitam desenvolver estratégia para estruturar os serviços de atendimento aos usuários de crack e seus familiares que estejam realmente em sintonia com as suas necessidades.

Enfim, é necessária a promoção da acessibilidade do tratamento de forma imediata e pelo tempo necessário considerando todos os aspectos e sintomas da doença sejam eles físicos, psicológicos ou sociais, com assistência de equipe multidisciplinar adequada e ainda buscar no lugar de vida deste as contradições, os problemas, causas e soluções para a drogadição, pois é nele que deve ocorrer a gestação da consciência cidadã. 


\section{GEOGRAPHY, ETHICS AND PUBLIC HEALTHINTHE CONTEXT OF ADDICTION}

Abstract: This text seeks to reflect how science can work together contributing to the treatment of chemical dependency and acting responsibly on its various aspects citing reductionism, where the paths to follow in order to win the crack ethically go through several ideas multiple theories, where geography were significantly contributes to help analyze the lived space and diagnose the various factors that do not interact or contribute to crack use.

Keywords: Treatment. Crack. Place.

\section{Referências bibliográficas}

BARBOSA, F. M. T. Imperialismo e produção do espaço urbano: indústria do amianto e a construção da cidadania em Minaçu (GO). 2013. 280f. Tese (Doutorado) - Programa de Pós Graduação da Faculdade e Filosofia, Letras e Ciências Humanas, Universidade de São Paulo (USP). São Paulo, 2013.

BARCELLOS, C. A Geografia e o contexto dos problemas de saúde. Rio de Janeiro: ABRASCO: EPSJV, 2008.

BARRIOS, S. A produção do espaço. In: SANTOS, M.; SOUZA, M. A. (Org.). A Construção do Espaço. São Paulo: Nobel, 1986.

BUCHER, R. Drogas e drogadição no Brasil. Porto Alegre: Artes Médicas. 1992.

CASTRO, J. Geografia da fome. 6. ed. Rio de Janeiro: Civilização Brasileira, 2006.

EISENSTEIN, E. Crianças e adolescentes: riscos, sexualidade, DST/ AIDS. In: Manual de prevenção ao uso indevido de drogas: subsídios para educadores sociais. Rio de Janeiro: NEPAD/VER - COSAM/ MS. 1998.

LEFEVRE, H. A produção do espaço. Tradução de B. D. Pereira; S. Martins. Paris: ÉditionsAnthropos, 2000).

MOREIRA, R. Repensando a Geografia. In: SANTOS, M. (Org.). Novos Rumos da Geografia Brasileira. São Paulo: Hucitec, 1942. 
RIBEIRO, M.; LARANJEIRA, R. O Tratamento do usuário do crack: Avaliação clínica, psicossocial, neuropsicológica e reabilitação. Ambientes de tratamento. São Paulo: . Editora Casa Leitura Médica, 2010.

SANTOS, M. A Natureza do Espaço. São Paulo: Hucitec, 1996.

SIENA, V.M., MESQUITA,W.A. Vulnerabilidades e fatores de ricos na vida de crianças e adolescentes. v. 20n 1 janeiro/março. . São Paulo: 2006.

STACCIARINI, J. H. R. Pluralidade, publicitação e multiplicação do fazer político. Ação da cidadania contra a fome. 2002. 420f. Tese (Doutorado em Geografia) - Programa de Pós Graduação em Geografia, Universidade do Estado de São Paulo. Presidente Prudente, 2002.

TUAN, Y. Topofilia. São Paulo: Dijiel, 1980.

TUAN, Y. Espaço e Lugar. São Paulo: Dijiel, 1993.

VELHO, G. (Org.) O Fenômeno urbano. Zahar, 4. ed. Rio de Janeiro: 1979. 